\title{
Difficulties and Countermeasures in Performance Management of Primary Health Care Institutions in China
}

\author{
Meng Zhou'1, Liqi Tian² \\ ${ }^{1}$ Qingdao University, Qingdao, China \\ ${ }^{2}$ Affiliated Hospital of Qingdao University, Qingdao, China \\ Email: zhoumengv@163.com
}

How to cite this paper: Zhou, M. and Tian, L.Q. (2019) Difficulties and Countermeasures in Performance Management of Primary Health Care Institutions in China. Open Access Library Journal, 6: e5068. https://doi.org/10.4236/oalib.1105068

Received: November 26, 2018

Accepted: February 25, 2019

Published: February 28, 2019

Copyright ( $\odot 2019$ by authors and Open Access Library Inc.

This work is licensed under the Creative Commons Attribution International License (CC BY 4.0).

http://creativecommons.org/licenses/by/4.0/ (c) (i) Open Access

\begin{abstract}
At present, the main dilemma faced by performance management of primary health care institutions is that the total performance salary is not high, the incentives caused by the imbalance of performance wage structure, the lack of perfect performance appraisal distribution system, and the performance management level of the dean of grassroots health institutions need to be improved. Performance management training courses for the characteristics of primary health care institutions are yet to be developed. It is recommended to actively implement the "two permits", increase the autonomy of distribution, increase the total amount of performance pay, and increase the proportion of incentive performance pay, so as to promote the professionalization of dean of primary medical institutions and attach importance to performance management knowledge training. Based on the positioning and characteristics of primary health care institutions, from the three stages of performance management curriculum, curriculum teaching and curriculum assessment, a set of performance management courses that meet the characteristics of primary health care institutions are designed.
\end{abstract}

\section{Subject Areas}

Diabetes \& Endocrinology, Health Policy

\section{Keywords}

Primary Health Care Institutions, Performance Management, Dean Professionalism

One of the basic grasps of deepening the reform of medical and health constitution in China is "strong grassroots". The health and health policy in the new era 
also put forward "focus on the grassroots level". Township hospitals and community health service centers are the window units that provide basic medical services and basic public health services directly to the masses. They are the cornerstone for establishing an orderly medical treatment order and promoting a graded diagnosis and treatment system. At present, governments at all levels have increased their investment in grassroots medical and health institutions year by year. The infrastructure and medical environment of grassroots medical and health institutions have been significantly improved. However, new large pots of rice have appeared. The main performance is: grassroots medical staff are not motivated, service efficiency is low, and performance is low. This study explores the current situation of performance management in primary health care institutions, finds the predicament of performance management, and proposes countermeasures.

\section{Introduction and Methods}

\subsection{Source of Information}

The data in this paper is derived from the 2017 Health and Family Planning and Talent Planning Monitoring and Evaluation and Questionnaire Collection. The primary health care institutions refer to township health centers and community health service centers. The directors of grassroots medical and health institutions refer to the president/deputy director of the township health center and the director/deputy director of the community health service center.

\subsection{Research Methods}

\section{1) Questionnaire collection}

The survey samples were determined according to a multi-stage stratified random sampling method.

First, the provinces (municipalities and autonomous regions) of the country are divided into six administrative regions, namely North China (Beijing, Tianjin, Hebei, Shanxi, Inner Mongolia), Northeast China (Heilongjiang, Jilin, Liaoning), East China (Shanghai, Shandong, Jiangsu, Zhejiang, Jiangxi, Anhui, Fujian, Taiwan), Central South (Hubei, Hunan, Henan, Guangdong, Guangxi, Hainan), Southwest (Sichuan, Guizhou, Yunnan, Tibet, Chongqing), Northwest (Shaanxi, Gansu, Ningxia, Xinjiang, Qinghai). Among them, North China draws Beijing, Jilin Province in the northeast, Anhui Province in East China, Hubei Province in Central South, Guizhou Province in the southwest, and Ningxia Hui Autonomous Region in the northwest.

In the second step, each sample province (city, autonomous region) draws one prefecture-level city (state). Each sample of the prefecture-level city (state) Health and Family Planning Commission is responsible for the grassroots health work deputy director, the grassroots health chief.

In the third step, the deputy director of the grassroots health work and the head of the primary health unit in charge of the health and family planning bu- 
reaus of all counties (districts, municipalities) in each prefecture-level city area are the subject of investigation.

In the fourth step, all community health service centers and township health centers in each prefecture-level city area shall have one dean/director and one deputy dean/deputy director. At least one middle-level management staff, one senior-level practicing (assistant) physician, one senior-age registered nurse, and one senior medical technician are included in the survey when extracting all community health service centers and township hospital staff.

A total of 8304 valid questionnaires were collected, including 1425 employees in community health service centers, 364 directors in community health service centers, 118 health and family planning executives, 923 township health centers, and 5474 township health workers.

\section{2) Interview method}

Using personal in-depth interviews, the qualified interviewers used the interview outline as an interview tool to conduct one-on-one interviews with the health workers in the sample area, the president of the township hospital, and the director of the community health service center.

\section{Results}

\subsection{The Total Amount of Performance Wages Is Not High, and the Approved Standards Are Unreasonable}

At present, although the "two permissive" policies have been proposed, the policy rules and implementation paths in primary health care institutions have yet to be further explored and improved. The primary health care institutions still maintain that they should not issue any subsidy or bonuses in addition to the approved total performance pay, and must not break through the status quo of the approved total performance payroll [1]. At the same time, the approved standards for performance pay of primary health workers are still based on the principle of the average salary level of local public institutions. It is difficult to reflect the characteristics of long training period, high occupational risk, heavy responsibility and technical difficulty in the medical industry [2].

\subsection{Performance Salary Structure Is Unbalanced and Insufficient Incentives}

At present, the performance pay of primary health care institutions is divided into two parts: basic performance pay and reward performance pay. The basic performance salary accounts for $60 \%-70 \%$ of the performance salary, which can reflect the workload and actual contribution. The proportion of reward performance pay is low, only $30 \%-40 \%$. Although this maintains public welfare to a certain extent, it also causes incentives. And with the gradual development of grading medical treatment, the increase of public health service programs, and the implementation of family doctor signing system, the work intensity of health workers in grassroots medical institutions as "gatekeepers" has increased signif- 
icantly, and the proportion of reward performance payrolls is low. In the interview, a dean mentioned: “Now don't let the task be fixed. If you don't decide the task, you will not see the doctor. You will go to the big hospital to see it. Sometimes you can see it even if you can see it". In the study, the survey respondents believe that the weakest link in the current performance management work is incentive policy, accounting for $51.6 \%$.

\subsection{Lack of a Perfect Performance Appraisal Distribution System}

The performance appraisal system of grassroots medical and health institutions should be classified according to the different characteristics of professional technology, management, work and other positions. According to the results of the assessment, we insist on more work and more rewards in the distribution, and focus on the key positions, business backbone and outstanding staff. The internal performance salary distribution of primary health care institutions should be tilted to positions that undertake public health services and clinical front-line tasks, such as general practitioners [1] [3]. However, there is still a lack of a comprehensive performance appraisal distribution system, which has led to the phenomenon of "big pot rice" and "averageism" in the process of grassroots performance management. In the interview, a dean mentioned: "Performance management is a very headache. There is no set of ready-made things that can really reflect more work, so this one is still a headache, so we are now fuzzy management. It's not very clear. It's often based on the habits of people. For example, there are still many issues to be considered, such as seniority issues. Some employees have been working here for so long, and they think their salary can't be too low. We have at that time, it needs to be reflected". In the survey, there are still $10.7 \%$ of the performance distribution methods of primary health care institutions adopting the "big pot rice" egalitarian distribution method.

\subsection{Dean's Performance Management Level Needs to Be Improved}

The chiefs of the primary health care institutions are mostly medical and excellent. Most of them are clinically selected and have advantages in medical technology, but lack systematic management knowledge training. The management method belongs to traditional experience-based closed management, which leads to lower management level of primary medical and health institutions. In the survey, the directors of the Community Health Service Center and the Dean of the Township Health Center concentrated on clinical specialties, accounting for $65.9 \%$ and $73.7 \%$ respectively. The health management profession only accounts for $3.7 \%$.

Dean of primary health care institutions received few management knowledge trainings. Most of the trainings received in the survey were concentrated below 5 times, accounting for $74.4 \%$. In the survey, the dean and staff believed that performance management was the weakest in all types of management work in 
grassroots health institutions, accounting for $42.4 \%$.

\subsection{Performance Management Training Courses for the Characteristics of Primary Health Care Institutions Need to Be Developed}

In 2010, the "Guiding Opinions on the Pilot Reform of Public Hospitals" issued by the five ministries and commissions, such as the former Ministry of Health, the Central Organizing Committee, and the Development and Reform Commission, emphasized that "the management system for the qualifications of the presidents of public hospitals, the selection and appointment of the public hospitals, and the promotion of Professional construction". The Interim Measures for the Administration of Leaders in Public Hospitals, implemented in January 2017, for members of the public hospital leadership group held by governments, institutions, social organizations and other social organizations at or above the county level, clearly require that public hospital leaders should pass state-approved Dean professional training [4]. However, there is currently no professional training for the characteristics of primary medical institutions, especially in performance management. This has caused the current performance management knowledge to be unacceptable at the grassroots level. In the interview, a dean mentioned: "Employees should use the system to motivate, also called performance management. I don't think it is useful for the balanced scorecard. I don't think it is used. I think there are several reasons. First, let's did not get through, learning is not in place. Second, and the positioning of rural health centers, it feels difficult to carry out in township hospitals...". Another dean mentioned: "If the training course is based on the survival of township hospitals, then the performance appraisal system is more important, which can increase the income of the hospital and the income of the workers. But the current performance appraisal is not good effect".

\section{Discussion}

\subsection{Decentralization, Increase the Total Amount, Adjust the Structure}

Actively explore and implement the "two permissibility", give the primary health care institutions autonomy, increase the total performance pay, increase the proportion of personnel expenditures to corporate expenditures, and increase the proportion of incentive expenditures-ensuring personnel expenditures. Improve the performance pay system of primary health care institutions, and lean forward to the frontline personnel, especially the general practitioners. A certain percentage is drawn from the balance of payments approved by the primary health care institutions, and they are used as incentives and welfare funds for employees. At the same time, explore the excessive salary mechanism and the overall growth mechanism of overall performance. Reward the excellent medical staff rooted in the grassroots for a long time, and enhance the sense of honor 
and belonging of the grassroots medical staff.

\subsection{Professionalism, Focus, Performance}

Adhere to the professionalization of grassroots deans and attach importance to the training of performance management knowledge. In recent years, the government has issued a series of documents on the professionalization and professional training of hospital deans, and proposed to strengthen the construction of health management talents, gradually standardize the conditions of hospital administrators, and form the requirements of professional talents. At present, China's primary health care institutions are similar to public hospitals. In order to implement national policy requirements, primary health care institutions are in urgent need of management professional training. At the same time, in the process of managing professional training, we must pay attention to the study of performance management knowledge, and solve the current dilemma of performance management of primary medical institutions, and effectively improve the performance of organizations and individuals.

\subsection{Based on the Standard, Meet the Needs, Based on Practice}

Based on the positioning and characteristics of grassroots medical and health institutions [5], starting from the three stages of performance management curriculum, curriculum teaching and curriculum assessment, a set of performance management courses that meet the needs of the dean of primary health care institutions are designed. With the launch of a new round of medical reform, the promotion of reform measures such as grading diagnosis and treatment, and the guidance of the "Healthy China" strategy, China has established the basic principles of "guaranteeing basic, strong grassroots, and construction mechanisms" in practice, and clarifying grassroots medical and health institutions. Therefore, in the setting of the performance management curriculum, it is necessary to closely integrate the actual needs of primary health care, so that the president of the primary health care institution can understand and master the concepts, principles, methods, systems and procedures of general performance assessment and management [6]. It is also necessary to form a full understanding and understanding of the nature, foundation, indicators, development, implementation, incentives, and evaluation of performance management. On this basis, master the basic processes and operational essentials of performance management and the main performance appraisal techniques, and finally be able to use the knowledge and skills learned to analyze and solve practical problems related to the performance management of primary medical institutions, and to specific departments or service projects. Design a practical performance evaluation and management plan. In the teaching of performance management courses, we must pay attention to the teaching of practical links to ensure that the training subjects not only master the theoretical knowledge of performance management, but also have the practical operation ability of performance management. In the 
assessment of performance management courses, through the construction of the evaluation tools based on the innovation ability and practical ability of the medical institution's medical institution directors, that is, from the previous theoretical assessment as the center, to the emphasis on the application of practical assessment; from the past The homogenization assessment is the center, and it is transformed into a personalized assessment that meets the needs and combines specificity. In short, the performance management curriculum should be based on accuracy, starting from the basics, starting from the grassroots level and expanding from the foundation. Strive to improve the ability of the performance management knowledge of the dean of the primary health care institutions, and enhance the practicality of the knowledge and skills learned.

\section{Conflicts of Interest}

The authors declare no conflicts of interest regarding the publication of this paper.

\section{References}

[1] Ministry of Human Resources and Social Security, Ministry of Finance and Ministry of Health (2009) Notice on Printing and Distributing Public Health and Grassroots Medical and Health Institutions to Implement Performance Wages.

[2] Zhang, Y., et al. (2017) Problems in the Salary System of Township Hospitals in China and Their Considerations. Health Economics Research, No. 12, 14-16.

[3] The General Office of the State Council (2018) The General Office of the State Council on the Reform and Improvement of the Training and Use of Incentives for General Practitioners.

[4] Yin, A., et al. (2007) Functional Positioning and Financial Input Mechanism of Primary Health Institutions. Chinese Health Economics, No. 12, 86-88.

[5] Lin, N. (2015) Research on Performance Salary System of Grassroots Medical and Health Institutions-Based on the Perspective of Equity Theory. Journal of Health Economics, No. 3, 24-26.

[6] National Health and Family Planning Commission (2017) Interim Measures for the Management of Leaders in Public Hospitals. 1-3. 